Session 2438

\title{
Utilizing Reverse Engineering to Explore the Design Process
}

\author{
Rebecca Sidler Kellogg, Roland Jenison \\ Department of Aerospace Engineering and Engineering Mechanics \\ Iowa State University
}

\begin{abstract}
Faculty at Iowa State University (ISU) have used the process of reverse engineering for the past five years to introduce lower division students to product design principles. This paper discusses the use of reverse engineering as a hands-on activity in the Engineering Design Graphics (ENGR 170) course. This activity was initiated with support from the National Science Foundation Synthesis Coalition. Students are assigned to teams of three to five members each and learn to work and collaborate with their colleagues to accomplish a given task. In this case the task is to dissect a product provided by the instructor to learn about design. Students investigate how the product performs, how its various systems operate, and what limitations exist in the design. As they disassemble the product, they are required to carefully document their procedure. They are asked to make sketches and drawings of the assembly and various components. The students study how the components were designed, what materials were used, how the parts were assembled, and how each component functioned as part of the whole. They consider the criteria and constraints that were met by the design and formulate a description of the primary need the product addresses. Students discuss how the various engineering disciplines contributed to the overall design and get a flavor for the collaborative nature of design. They also consider possible uses for the product as well as how the product might be misused. In addition, students are asked to think about other ways the design could have been achieved. In some of the projects students are asked to design a test to discover how well the product performs its tasks. Both written and verbal communication are emphasized. Students are required to submit a formal written report about the product they studied. They also learn about the importance of verbal communication in design through the teamwork experience. After the product has been thoroughly studied, the students are often required to reassemble it so that it once again works. Several products have been used for the dissection project at Iowa State University including a fabric shaver, a computer mouse, a Dremel FreeWheeler, a Kodak FunSaver ${ }^{\mathrm{TM}}$ camera, and a mobile robot built from a kit of components designed at Iowa State. Various aspects of these product dissection projects are discussed in this paper. The reader will learn how each of these projects was used in the course to enhance the students' design experience. This paper also looks at student and faculty response to hands-on, reverse engineering projects as part of ENGR 170. The paper concludes with a brief discussion of the future directions of this project.
\end{abstract}

\section{Introduction}

Faculty at Iowa State University (ISU) have used the process of reverse engineering for the past five years to introduce lower division engineering students to product design principles. The ef- 
fort was initiated as part of the National Science Foundation's Synthesis Coalition, a group of eight colleges and universities that emphasizes a hands-on approach to engineering education.

Since most entry level engineering students do not possess the needed analysis and technical skills, it is often helpful to start introducing them to design by allowing them to investigate, in detail, existing products. These hands-on projects let students use their experience and intuition to study something that has already been developed as a result of the engineering design process. It is this design process that students need to master as part of their preparation for an engineering career.

The reverse engineering process includes a step by step dissection of an existing product's assemblies and components to learn about the design. In order to access components housed in the interior of the product, product dissection is required. Students are provided the product and any necessary tools to take the product apart. Students are also provided with instructions and safety warnings. They are prompted to make appropriate observations as they proceed to disassemble the product. The dissection takes two laboratory periods and the entire project requires approximately three weeks. At the completion of the project a formal report is submitted by each team that summarizes what the students learned about their product and engineering design.

\section{Procedures and Objectives}

The students are initially divided into teams of three to five members each. The teamwork experience provides students with an opportunity to discover the advantages and disadvantages of working with others. Since collaboration will be a part of their future real world experience as they pursue careers as engineers in industry, it is important to immerse them in such an environment early in their education. Design is a perfect setting to do so in that design is inherently collaborative; good designs are seldom achieved by an individual working alone. The collaborative nature of teamwork naturally enhances the students' experience. They learn a great deal by sharing ideas and interacting with each other. Each member brings past knowledge and experience to the project. They learn to divide responsibilities and capitalize on individual talents. Through the experience of working with others, students also improve their communication skills. They quickly find that these skills are necessary for survival in a cooperative setting.

At the beginning of the dissection project each team receives a product and necessary tools. Many of the students have never experienced this type of hands-on project and are unfamiliar with using tools and taking things apart. Although some students have a natural inclination for this activity, many are fairly inexperienced. The faculty must be aware of this and encourage each student to actively participate. During the dissection process the instructor circulates among the teams providing extra guidance and answering questions.

One of the first things students are asked to think about is what problem the product solves or what need it addresses. In some cases the students are asked to consider the advantages of the product in comparison to other products available to meet the same identified need. In the case of the mobile robot, which will be discussed in more detail later, students are asked to consider how similar products might be used in industry. Students are asked to discuss possible functions the product may have, as well as alternative ways the product may be used or misused. By de- 
lineating possible uses, students learn how to transfer knowledge of one product design to another. This task also gives them the opportunity to appreciate the care that must go into design to safeguard against consumer abuse.

Prior to the actual dissection, students are asked to think about what they expect to find. They are prompted to examine the outside features of the product and hypothesize about how various operations are performed. Once they begin the dissection process, they will continue to explore its mechanisms and component interactions, thus confirming or revising their explanations of how things are put together and how they work.

Students are also provided with an instructional handout, thus, they are not completely left to their own resources. The instructions guide the students through the thought process and the physical dissection. There are appropriate warning messages and safety notices. At each step of the dissection process the students are prompted to make appropriate observations. Part of the assignment is to keep a careful written record of what was done. Each team member must take a turn as the group note taker. The students are also asked to make sketches or formal drawings of individual parts and assemblies. As they progress through ENGR 170 they will produce AutoCAD drawings of selected components as well as the entire assembly. Students have tended to develop better sketching and drawing skills when they are interested in the objects they are working with. Students are also required to construct a parts list including part descriptions.

As the students progress through the dissection process they are asked to theorize about how the components were made and how the product was assembled. Students are also asked to analyze the materials used for the components in the product and speculate on why the materials were selected. They discuss why certain design choices were made and what other alternatives might have been available to the designer. This includes deciding what criteria and constraints were met by various aspects of the design. Requiring students to identify criteria and constraints on existing products helps them to develop the ability to determine the applicable criteria and constraints for new, open-ended design projects.

The students also discuss which engineering disciplines were involved and how. At this stage of their education most students are only vaguely familiar with the different disciplines so it is important for them to begin to recognize the contributions made by each discipline. The introduction to the different engineering disciplines may help some students make a better, more informed career choice. It also re-emphasizes the collaborative nature of design.

After the students have thoroughly studied the product, they are usually required to put it back together so that it works as it did originally. They rely on their written notes and experience. The faculty then check to be certain that the teams achieved this step. If they need some assistance, the faculty will help them. This part of the assignment is considered complete when the instructor verifies that the product once again works properly. Currently, the FunSaver ${ }^{\mathrm{TM}}$ camera project is the only dissection project that does not require re-assembly. The dissection process in this case is destructive and re-assembly is not possible.

Many of the dissection projects include supplemental product information handouts. Students are encouraged to perform some additional research about the product. They can explore infor- 
mation available on the Internet, at the university library, from industry sources, or from any other source at their disposal. When students become enthused about their product, faculty find that they tend to exceed the project expectations and acquire additional knowledge and information. It is very exciting to see students demonstrate such self-motivation. By the end of the project most of the students are very knowledgeable about the product's design.

At the completion of the dissection process a final formal written report is submitted by each team. This report completely summarizes what was learned about the product. The students on a team work on their report together and must each sign off on the final document prior to submission.

\section{Products Studied}

\section{Fabric Shaver}

The Perfection Fabric Shaver was one of the earliest dissection projects used at Iowa State. This product was studied, tested, and evaluated by teams of students in ENGR 170. The first task for each team was to define the problem the product solves. In this case, the problem was the removal of fuzz from material. Students also considered other solutions to meet the identified problem including sticky tape, scissors, clippers, razor, and tweezers. Based on these simple alternatives, the students decided the main constraint of the design was that the product needed to be sold for less than five dollars.

As with every dissection project, students were provided with instructions for the dissection procedure. As they proceeded to disassemble the shaver, students were asked to keep accurate written records and make appropriate sketches. From these records, they were asked to create a parts list and assembly instructions. Students also made sketches of the components and the assembly. They also created an exploded assembly drawing of the product. Students investigated the electrical circuit that operated the shaver and created a simple circuit schematic which was provided in the handout material.

Students discovered what they considered a major design flaw in the way the lint compartment is attached to the shaver. The connection is a snap fit which is very tight when the product is new, but begins to wear quickly. After it wears, the compartment falls off easily. The students proposed designs where the compartment would slide on a track or be latched in place. Students also thought the design could be improved by including a larger space between the fan blades and the inside of the shaver to reduce clogging.

After the product was reassembled the students conducted tests to determine product performance. First, they used a strobe light to determine the average motor speed. Next, the teams designed a performance test where the shaver was used on various types of fabrics and evaluated according to the following criteria established by students; clogging, material damage, fuzz removal rate, ease of use, and quality of fuzz removal. Typical conclusions from the test were that the shaver will clog when used on fabrics other than wool, light and loose-weave materials were easily damaged, and it took longer to clear fuzz from heavier materials. 


\section{Computer Mouse}

Another early dissection project was a MousePlus ${ }^{\mathrm{TM}}$ Model MO-260 computer mouse. Students dissected and examined the mouse in order to develop an understanding of the purpose, functions, basic operating principles, and overall design of a standard computer mouse. The teams first examined the physical components on the exterior of the mouse which consisted of a cord, a computer interface, three buttons, and a casing which consisted of a lower and upper section. The students measured the physical dimensions and produced sketches of the exterior of the mouse. Students identified the material the casing was fabricated from as a light, hard plastic dyed a pale gray-brown. They decided the material was selected because it was inexpensive, durable, and easily molded. Students also observed that the shape of the mouse casing and position of the buttons were ergonomically designed. Next, the casing was removed and the interior components of the mouse were then examined. These components included thin plastic disks with twenty-four cogs attached to axles. One axle was parallel to the width of the mouse, and one was parallel to the length. The disks were fabricated from plastic. A light roller ball made from hard, dense, inelastic black rubber was also found on the interior of the mouse. The students decided this material was most likely selected because of it was light weight, and would not distort the readings of the mouse's movements by slipping. There was also a spring tension device in the corner opposite the two disks. This device kept the ball properly aligned. The roller was also supported by a circular piece of plastic snapped into the lower housing. Other components included an electronics board, thumbscrews, and an MS/PC mode switch.

The students then identified the MousePlus as an optomechanical mouse based on the roller/disk configuration and electrical sensors. The cogs generate electrical signals which break beams of light from two pairs of photodetectors and light-emitting diodes (LEDS).

This project included the requirement for the students to design a test to determine the effects of using different mouse speed settings. The students determined the length of line drawn in SilverScreen when the mouse was moved through three rotations of the disks at various mouse speed settings. They found that there was considerable error in the measurements. This led the teams to investigate the reasons. They discovered that with the top half of the casing removed additional light from the room affected the results. This led them to realize the purpose of the black color used for the roller ball and cogs.

Students also investigated other devices that operate on the principle of breaking a beam of light. They found examples in security systems and video games. Students also looked at other types of computer mice including mouse pens, cordless mice, trackballs, and joysticks.

The teams also made suggestions to improve the design such as increasing the number of cogs to improve the accuracy. Students also thought there was room for improvement in the design of the shape.

The teams that investigated the computer mouse submitted final reports that included formal drawings and sketches. They also were required to investigate many of the competitive products available. 


\section{Dremel FreeWheeler}

The Dremel FreeWheeler was designed as a high-powered, compact, cordless multipurpose tool with interchangeable bits for drilling, sanding, and buffing. Dremel donated these tools to ISU for the dissection project. Students identified several design constraints and criteria. The tool must be capable of operating effectively when powered by NiCad rechargeable batteries for up to one hour. The batteries need to be effective for at least 35000 charges. The battery charger must operate off of a standard AC $120 \mathrm{~V}$ source. The drill must be capable operating at different speeds and using several different tips for various jobs. Ease of use is also important to the overall design. The tool must be priced at $\$ 100.00$ or less.

Students started by examining the exterior of the tool. The casing was made of tough plastic which was strong, easily molded, and inexpensive. The tool was designed to fit comfortable in the hand. The students then examined the interior components. They found the main gear and drive shaft, and bit assembly. These components were fabricated from high strength durable metal alloys with polished finishes. Students discovered that polished surfaces are used to minimize friction and maintain operating conditions during use. They found that the gear coupling was made from molded rubber so that it could easily slide when the shaft lock was engaged. The students also found that the motor was covered with sheet metal with air vents for temperature control. Students examined the switch assembly that connects the motor to the batteries.

Students created assembly drawings for the Dremel tool and identified each component and system on the drawings. They went on to identify how the tool works. They discovered that when the high speed setting was selected, all five batteries were employed, but when the low speed was selected only three batteries were required. The students also discovered how the motor works and in turn operates the drive shaft through the gear coupling. They studied the shaft lock which can be engaged for non-motorized use and looked at the bit assembly which consists of a holder, a spring, and a fastener.

As with all dissection projects, students delineated the roles of the various engineering disciplines in the final product design. Students acknowledged that mechanical, electrical, industrial, and material science engineers played major roles in developing the Dremel FreeWheeler.

After the students became familiar with the current design, they went on to consider design improvements. Suggestions included additional power capability, extended battery life, and additional types of bits. They also discussed how the product might be misused. Students designed a performance test for the tool in which they characterized how it performed when used on various materials and for different applications. In general they found the Dremel FreeWheeler to be a reliable and effective tool.

\section{Kodak $^{\mathrm{TM}}$ FunSaver ${ }^{\mathrm{TM}}$ Camera}

ISU can purchase used Kodak ${ }^{\mathrm{TM}}$ FunSaver $^{\mathrm{TM}}$ cameras for only five cents. This is the only project done as of yet at ISU where the students do not reassemble the product after dissection. The camera contains small gears and components which are interesting to learn about. Since this project includes destructive dissection, students have access to a 3-dimensional computer anima- 
tion that provides them with information about the sequence in which the dissection should proceed.

This single use camera was designed to be easy to use, compact, and inexpensive. As part of the initial assignment, students identify what they think the primary need is that the product meets. Two of the typical needs usually considered include providing a means for taking photos if a camera was forgotten at home and providing a camera for consumers who can not afford the expense of owning one. Students are then asked to determine the constraints and criteria placed on the camera design. Criteria include low-cost mass production, easy use, international marketability, easy film removal, attractive packaging that is both light and moisture resistant. Constraints identified by students include the availability of an automatic flash, focus-free lens, physical dimensions, and low cost. Students study how the constraints and criteria were satisfied. For example, in the case of the flash, they learn that a battery charges a capacitor which subsequently discharges resulting in the bright flash. Students also carefully study the mechanism that controls the shutter and discover the way in which it has been integrated with the flash. The groups that recognize low cost as a criteria sometimes also identify it as a possible constraint. In order to keep costs low, many optional features like picture dating or automatic timers have to be excluded.

The camera is assembled from simple parts including a capacitor, diodes, circuit board, halogen flash, battery and clip, molded plastic housing, plastic lenses, plastic film spool, plastic cam, gears, and film. A thumbwheel is used to advance the film which advances a sprocket which drives a cam. The cam advances the film counter and winds the spring of the lever energy system. When the film has advanced far enough the lever system locks into place. The lever system is tripped when the button on the camera is depressed. This releases the spring which opens the shutter to expose the film. The various materials parts were fabricated from were also examined. These cameras contain parts made from steel, brass, polymethyl merhacylate, paperboard, and nitrite compound. Students surmise that these materials were selected because of their strength, texture, durability, and producibility. Through some research students find out that over threefourths of the components were reused or recycled. During team discussions students identify the various engineering disciplines that contribute to the design including electrical engineering, mechanical engineering, chemical engineering, industrial engineering, and material science. Every team must specify how these disciplines contributed to the final product.

The students also discuss ways to improve the present design. They realize that the square corners are uncomfortable to hold and make suggestions about rounding the edges to improve the situation. The current battery employed in the design is a AA-size Kodak brand. One group suggested that using a rechargeable battery might be a better alternative. Another suggestion offered by previous teams is that a left-handed model might be successful.

As with any dissection project, each team must submit a final report discussing its findings for the FunSaver ${ }^{\mathrm{TM}}$ camera. Included in this formal report are drawings of the camera assembly and internal components. Some teams become interested enough to purchase a new version of the camera to evaluate how it performs. Many students perform additional research and include color photos of the camera and the dissection process. 


\section{Mobile Robot}

During the past two years Iowa State has incorporated mechatronics into ENGR 170. Defined as the application of complex decision making to the operation of physical systems, mechatronics is usually introduced in upper-level electrical and mechanical engineering courses. However, the infusion of microcontrollers in nearly all phases of everyday life indicates that all engineers should have a working knowledge of mechatronics concepts and their impact on products, processes and system design.

Teams of three or four students are provided with a pre-assembled mobile robot called an ankle grabber, shown in Fig 1. This robot is constructed from simple components designed at Iowa State plus wheels, motors, and other standard parts. These components are included in a kit furnished to the students. A parts list can be found in Fig 2.

The teams reverse engineer the ankle grabber to evaluate its performance capabilities, limitations, and the control system functions. Students are provided with instructions necessary to dissect, test and reassemble the robot. Prior to dissection, students measure the overall dimensions and determine an approximate center of gravity. They also perform speed and maneuverability tests on the vehicle. The speed test consists of timing the robot as it crossed a distance of ten feet. Students are encouraged to devise methods to improve the speed performance. The most common design alteration they make is adding double sticky tape to the wheels to increase traction.

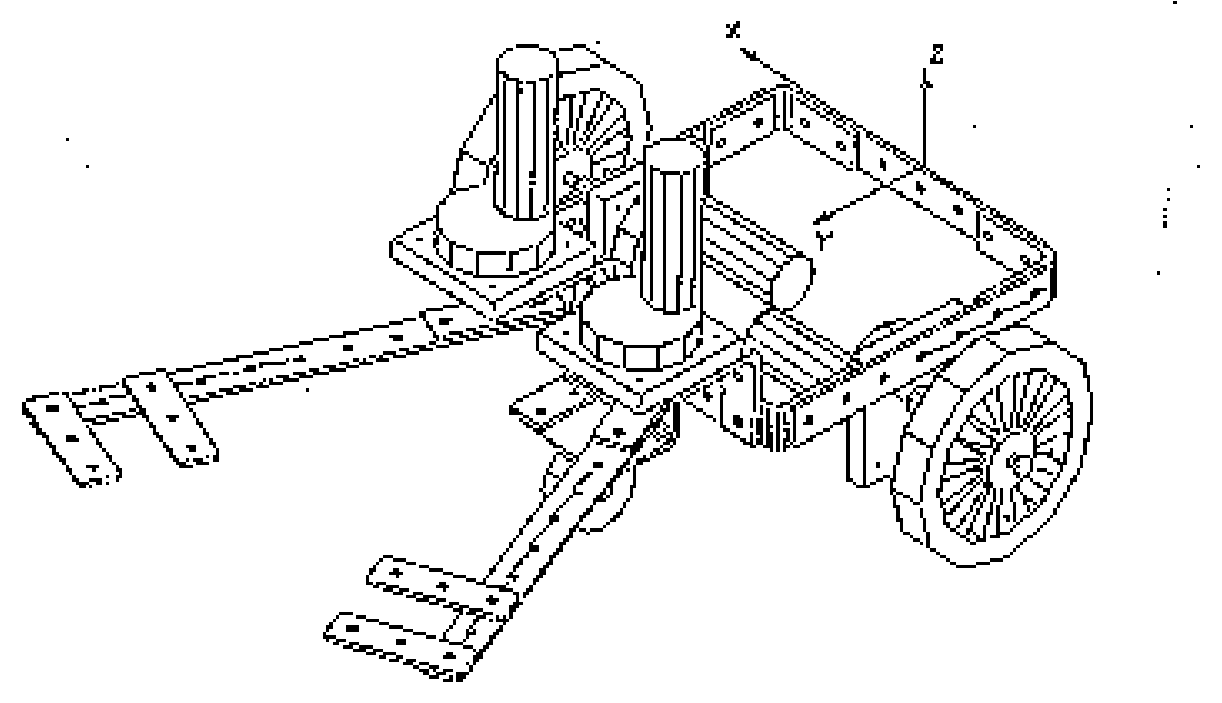

Fig. 1. "Ankle Grabber" Mobile Robot 


$\begin{array}{lclr}\text { Standard Part } & \text { Quantity } & \text { Manufactured Part } & \text { Quantity } \\ \text { Swivel Caster } & 2 & \text { 11-hole arm } & 8 \\ \text { Coupling } & 4 & \text { 7-hole arm } & 16 \\ \text { Wheel } & 4 & \text { 3-hole arm } & 8 \\ \text { DC motor } & 4 & \text { L-bracket } & 12 \\ \text { Clevis pin } & 4 & \text { Right-hand caster bracket } & 2 \\ \text { Pin clip } & 4 & \text { Left-hand caster bracket } & 2 \\ \text { Hose } & 1 \mathrm{ft} & \text { T-adapter } & 4 \\ \text { 1/2" 10-32 screws } & 25 & & \\ \text { 3/4" 10-32 screws } & 25 & & \\ \text { 2" 10-32 screws } & 4 & & \\ \text { 10-32 nuts } & 50 & & \\ \text { Screwdriver } & 1 & & \\ \text { Open-end wrench } & 1 & & \\ \text { Allen wrench } & 2 & & \\ \text { Wire cutters } & 1 & & \end{array}$

Fig. 2. Cyclotronics Kit Parts List

Next, students connect the ankle grabber to the computer interface box. Prewritten code is used to manipulate the robot. In this exercise students become familiar with computer interfaces. After they learn how the provided code operates, they make simple changes to parameters set in the code to alter the robot's movements.

As they proceed through the disassembly student are required to keep thorough written records of procedures and parts, including part functions. Based on these records, students create a parts list and set of assembly instructions.

Students are asked to think about ways similar products could be used. Some of the discussed applications include line painters for floors or roads and radioactive material handlers. Unique to the mobile robot is the design requirement to modify the present design to perform a specified new task. In this portion of the project, students must apply knowledge from the original design to the new design.

At the end of the project each team is required to submit a formal written report that summarizes the dissection activity. They are required to create both informal sketches and design drawings of the ankle grabber and their new design. 


\section{Student Response}

Students were asked to complete an anonymous survey regarding their dissection experience. The survey was given late in the semester so that the students could better reflect on their entire design experience and how the dissection project impacted it. The results of the survey were positive. Students recognized the dissection experience as a positive model of engineering. Their perceptions of engineering improved after they completed the project.

During the fall semester, 1996, two different products were dissected: the Kodak ${ }^{\mathrm{TM}}$ FunSaver $^{\mathrm{TM}}$ camera, and the mobile robot. Students were asked to record their overall satisfaction level for the dissection project on a scale of 1 to 10, where 1 represents not satisfied and 10 represents very satisfied. The satisfaction level for each product was averaged, however, no statistically significant difference in satisfaction was found between the means of the camera and the robot. Thus, the overall mean, 8.01, is representative of the student satisfaction with their dissection experience. A breakdown of the responses for all students can be seen in the chart below. It is interesting to note that there was not one response below 5, indicating that not one student reported being dissatisfied with their dissection experience.

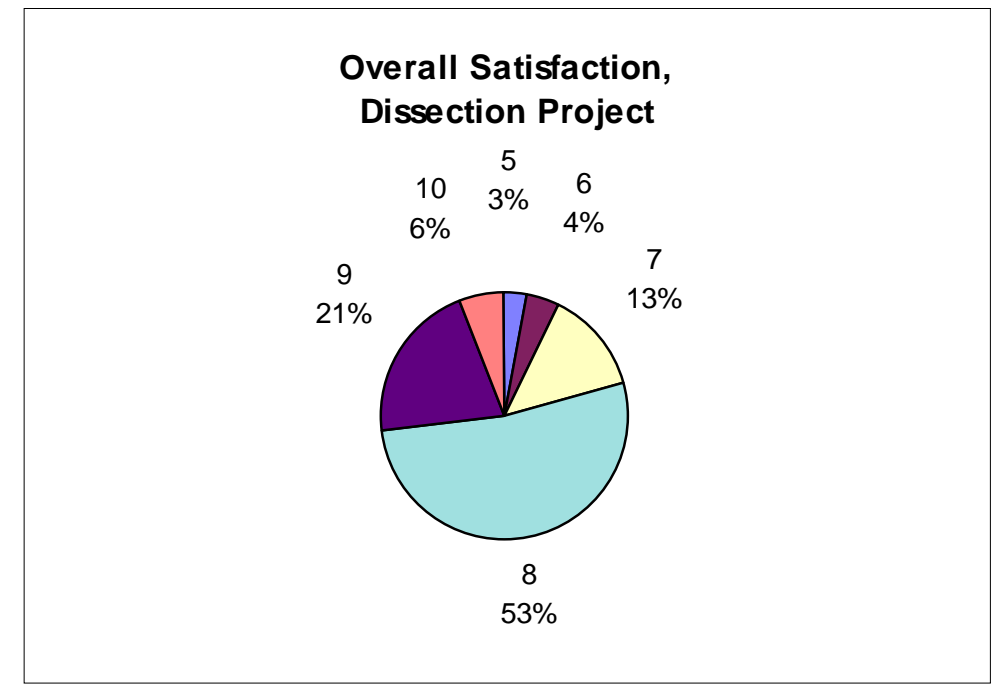

Several other survey results are worthy of mention. First, there was a very positive response to the use of graphics in a real world situation. Second, students overwhelmingly recognized the advantages of teamwork. They appreciated having several sets of hands to share the work. They also observed that the quantity of ideas and suggestions was increased leading to a deeper understanding of the product and the design process.

There were also results that pointed to areas where improvements to the project can be made. Students do not receive an adequate introduction to the manufacturing process. They also do not gain an appreciation for the different engineering materials available. These findings suggest that ISU needs to strengthen this aspect of the project with supplemental information and better questions for the students to consider as they study the product. 
One of the results that was surprising is that students do not grasp the importance of verbal communication in teamwork. There appears to be a failure on their part to recognize that verbal skills are important to successfully completing a team project. Instructors need to find a way to convey this to students.

Finally, when students were asked what they like least about their dissection experience, their answers typically reflected that they disliked tasks that were detailed oriented like counting and measuring pieces, creating drawings, and most of all writing the formal report. ISU needs to develop a procedure to make this an integral part of all projects. The process needs to be enhanced so that students perceive it as important and meaningful.

\section{Faculty Observation}

Faculty members that regularly teach the freshman design course were also asked to comment on their perceptions of dissection project. Faculty have observed that students are better able to identify the steps of the design process when they are asked to complete an open-ended design project later in the semester. They can focus on the necessary design steps and have less difficulty establishing criteria and constraints for their new problem. Thus, it appears that the dissection project is an effective introduction to design.

Faculty also noted that they observe increased student interest in learning the graphics concepts introduced in this course when they can apply the techniques to real world situations. This was confirmed by the students by their favorable response to this question on the survey discussed in the previous section. Students have also demonstrated an increase in interest in learning as they take possession of their product. Many teams perform beyond expectations and turn in reports that exceed the requirements provided to the students.

\section{Future Directions}

Based on the results of the surveys, plans are being made to strengthen the areas of the project that are weak as well as develop the communication aspects of the project so that students better recognize how this project enhances their skills in this area.

Approximately 600 students take this course at Iowa State each year. Therefore, effort to develop new product dissection projects is ongoing. Currently, several new products are being investigated and new projects are being designed.

\section{References}

Vincent Ergolano, “Designing Freshman,” ASEE Prism, April, 1996, p. 21-23.

Interviews with John Jacobson and Steve Mickelson, both professors in engineering at Iowa State University. 


\section{Biographies}

Rebecca Sidler Kellogg is currently pursuing a Ph.D. in Engineering Mechanics at Iowa State University. She has been involved with the National Science Foundation's Synthesis Coalition at Iowa State for four years working in areas of mechatronics, product dissection, and courseware development. She has a B.S.M.E. (1985) and M.S.E.M. (1993) from Iowa State University.

Rollie Jenison is a professor of aerospace engineering and engineering mechanics at Iowa State University. He has been involved in design graphics education for over two decades. He is a long-time member of the Engineering Design Graphics Division (EDGD), having served as Division Chair in 1986-87, and was the recipient of the EDGD Distinguished Service Award in 1996. 